\title{
Erratum to: Turbulent Spot in Linearly Stable Taylor Couette Flow
}

\author{
Arjang Alidai ${ }^{1,2}$ • Arnoud J. Greidanus ${ }^{1}$ - René Delfos ${ }^{1}$. \\ Jerry Westerweel ${ }^{1}$
}

Published online: 11 November 2015

(C) Springer Science+Business Media Dordrecht 2015

\section{Erratum to: Flow Turbulence Combust DOI 10.1007/s10494-015-9664-7}

In the original online publication of this article the following authors were missing: Arnoud J. Greidanus, René Delfos, and Jerry Westerweel. Upon further consideration they needed to be added. This has now been corrected.

The online version of the original article can be found at http://dx.doi.org/10.1007/s10494-015-9664-7.

\section{Arjang Alidai}

arjang.alidai@gmail.com

Arnoud J. Greidanus

A.J.Greidanus@tudelft.nl

René Delfos

r.delfos@tudelft.nl

Jerry Westerweel

j.westerweel@tudelft.nl

1 Laboratory for Aero \& Hydrodynamics, Delft University of Technology, Mekelweg 2, 2628 CD

Delft, The Netherlands

2 Department of Industrial Hydrodynamics, Deltares, P.O. Box 177, 2600 MH Delft, The Netherlands 